\title{
The impossible necessity of Al governance
}

\author{
J. Peter Burgess ${ }^{1}$
}

Published online: 27 September 2021

(c) The Author(s), under exclusive licence to Springer Nature Switzerland AG 2021

The title of this volume announces the ambition to examine the relationship between artificial intelligence and governance by mapping the challenges for a 'sustainable digital ecosystem'. As might be expected, the original and engaging contributions to the issue approach this question from a variety of points of view, with varying assumptions, theories and data. The six pieces reflect no less than six distinct paradigms each of which engages its own range of concepts, experiences, and empirical realities, all circumscribing, in one way or another the notion of 'artificial intelligence' and the perspectives for its governance within such an 'ecosystem'. To make their arguments, the contributions must position themselves both in relation to 'artificial intelligence' and a certain 'ecosystem'.

The task may seem insurmountable, and to be direct, it is. And yet the somewhat counterintuitive point I want to make in this brief piece is that the insurmountability of the task that lies before each contributor is itself the only chance for preserving the value of human life against the technological, social and moral reality of artificial intelligence. In short, the impossibility of creating a stable, homogeneous, balanced, unambiguous, universal, timeless system of governance may give us the only assurance of a future shared by artificial intelligence systems and human values.

This is why the emphasis put on the 'digital ecosystem' in the special issue concept and its thematisation in several of the contribution is so crucial. What is, after all, a digital ecosystem? Of course for the natural scientific field of 'ecology' term borrowed from the lexicon of biology. It is a term that seems to be used more frequently in a metaphorical sense, denoting a system characterised by a harmonious totality than a biological system characterised by organic, naturally occurring components that mutually regulate each other for the well-being of the whole. A natural ecosystem

\section{J. Peter Burgess}

james.peter.burgess@ens.psl.eu

1 Chair in Geopolitics of Risk, Ecole Normale Supérieure, Paris, France is autonomous toward the external world, but co-dependent internally, interaction and intertwined in complex and variegated ways. (Ironically where the terminology of biology is increasingly exploited to provide metaphors for the technical world, such as 'eco-system', the institutional, bureaucratic terminology of 'governance' is increasingly applied to components of organic systems.)

This comparison between an organic and inorganic system helps us to clarify what can possibly be meant by a system, and what system-thinking implies for social planning in the age of AI. A system is an ensemble of interrelated elements that make up a coherent whole, a set of elements and activities that, together, and under the condition that the system is functioning adequately, that it contributes to a purpose, a meaning or an objective. This purpose is the meaning of the system, its unique essence, its individual, and identifying characteristic. It's what makes the system a system.

Systems theory, which has the vocation of explaining how such systems functions, the condition for their successful outcome, or for its failure. The theory is particularly adapted to technical systems, like computers and computer programmes. This is because their reach is finite and thus the scope and limits of the system is clearly defined and its purpose can be discretely evaluated, or as the case may be, modified or otherwise re-purposed. Sociologists have also made significant use of system theory. If one takes as a starting point, the assumption and the concept that society is a system, then considerable insights canned be gained by studying the way that society's components interact, as well as how its frontiers are formed, and exceeded. A technical system does not embody values, has no moral design, no affective meaning. A technical system executes; that is all.

It is therefore easy to imagine that there are important differences between systems theory when applied to a technological or a social system. Where borders of a technology system are more or less discreet, social systems have more fluid borders; where technological systems obey in the best of cases the intentions of their designer, social systems are made up of human beings and the institutions and practices 
they interact with. They are organic, malleable; they evolve, develop and reorganise.

This opposition between the technical and the social is of course a false one, a straw-man. The social system in which any technical, or in particular, AI system is deployed, flows in and through that system, just as the technical apportioned logics, the digital quantifiers, 2-dimensional reasoning, and not least economic standards, and quantified measures impose themselves upon society. This is the meaning of the 'digital ecosystem' - the 'technification' of the social and the socialisation of the technical.
Making sense of this paradox is the challenge these contributions face. It can never be a question of resolving it. The challenge posed by this thematic issue consists not of resolving it, but of defining the terms of living with it.

Publisher's Note Springer Nature remains neutral with regard to jurisdictional claims in published maps and institutional affiliations. 